\title{
ECONOMETRIC MODEL OF NATIONAL ENVIRONMENTAL POLICY ACT TIMBER PROJECTS
}

\author{
JAROD DUNN \\ Colorado State University, USA
}

\begin{abstract}
In this paper, I analyze the cost for 72 United States Forest Service National Environmental Policy Act (NEPA) timber projects over the period 2006-2016. Project costs exhibit economies of scale, over project size. That is, a proportional increase in project acres may result in a proportional increase in cost savings for NEPA projects. Moreover, projects with biota that are recognized by the Endangered Species Act (ESA) add to the complexity of projects, requiring more intensive analysis, which has direct cost effects. The results suggest that all equal projects that contain an ESA species are $51 \%$ greater in project cost. As a result, the presence of an ESA animal likely presents a disincentive for prospective projects to be undertaken by NEPA planners. The implication is that the cost of NEPA ESA analysis may not be a prudent budgetary undertaking, when comparing acreage to an area without an ESA, for project planning.

Keywords: NEPA, environmental planning, cost function, endangered species, timber projects, Forest Service.
\end{abstract}

\section{INTRODUCTION}

There is great demand in environmental policy making for improving and increasing the simultaneous use of analytical tools and deliberative processes. Due to a high degree of complexity, uncertainty and ambiguity, a combination of thorough analysis and informed deliberation is clearly useful and important for environmental appraisals and decisionmaking [1]-[4]. Substantial environmental and economic decisions are made on public lands and public land management continues to be a controversial arena particularly concerning timber harvest decisions [5].

One of the most polarizing pieces of public land legislation is the National Environmental Policy ACT (NEPA) of 1969. A 2002 study found that the United States Forest Service alone spends an estimated $\$ 250$ million annually on the NEPA planning process [6]. Another study revealed that in 2006, nearly 8,000 Forest Service employees were engaged in the NEPA process with nearly $\$ 365$ million spent on these planning engagements [7]. In 2012 the Council on Environmental Quality (CEQ) issued 40 Code of Federal Regulations (CFR) parts 1500-1508 calling for more efficient and timely reviews of NEPA documents.

NEPA costs vary across Forest Service projects and that variation can be attributed to a variety of factors. For instance, if a timber removal project is proposed in an area containing animals that fall under the Endangered Species Act (ESA), then the planning process (NEPA) will be more intensive, and likely costlier. Understanding how these costs vary across different forest projects provide valuable information when trying to determine the cost of NEPA for a timber-harvesting project and for budgeting decisions within the agency. If a collaborative effort for timber harvest between a private entity and the Forest Service were to take place, then these cost estimations could be used for a benefit-cost analysis for assessing a project location. The Forest Service would benefit with the lowest cost for performing the NEPA analysis, and the private entity would likely face less risk of litigation, and a shorter time frame for project implementation.

The Forest Service begins every year with a budget constraint (appropriated from Congress) and must make decisions on how to allocate their funds to maximize the benefits 
that the forest provides; whether this be recreation, conservation, or wood products. The results of this analysis will aid in that decision-making process by identifying areas where costs could be minimized. While not to be taken as a "silver bullet" to predict the costs of NEPA projects, the model attempts to be a powerful tool when making NEPA decisions. For example, if there were multiple forest systems that contained the desired timber utilization properties (whether biofuels, logging, or treatments), the planner could use the tool to examine the sites. This includes both qualitative and quantitative characteristics. With this tool, the planner could then make a decision amongst different NEPA alternatives that would result in the lowest cost, all else equal.

Economies of scale are also estimated from the NEPA cost function results of the model. Economies of scale and scope are typically estimated with cost functions that are common to all firms within an industry, whether or not they specialize in a single output or produce multiple outputs [8]. While economies of scope are not within the bounds of this analysis, a qualitative discussion is included. The internal structure of the firms in this analysis, where the firms are represented by different forests within the Forest Service, are assumed to be the same. For example, each forest employs resource specialists that work on the different sections of a NEPA document, such as a hydrologist, wildlife biologist, or air quality expert.

There is a developed area of literature surrounding the litigation factors and associated practices encompassing the NEPA process, but there has been little to no effort to estimate a cost function for the Forest Service's NEPA efforts. Hence the effort of this paper is to propose a NEPA specific econometric procedure to estimate the Forest Service's NEPA cost function.

The organization of this paper begins with a brief overview of the federal process to complete NEPA, then a detailed illustration of how the Forest Service prepares NEPA documents. The analysis continues with a brief discussion of cost functions and how they apply to solving the social planner's problem. This is followed by a literature review of cost function estimation analyses and the appropriate econometric model. The next section summarizes the data used for this analysis. This is followed by an econometric model of data gathered for the different forests in Region 1 of the US Forest Service. The findings of the model are analyzed and contextualized into a framework ideally to aid in finding a cost effective NEPA area for timber harvest. This research further elucidates the understanding of the cost function associated with the NEPA process.

One of the limitations of this analysis is that the costs of legal expenses incurred by the Forest Service with a contentious project are not directly estimated. Estimations of NEPA project cost variables outside of timber product projects (i.e. camp grounds, oil and natural gas development, recreational improvements, etc.) are not within the bounds of this paper and were therefore not included. Only costs faced by the Forest Service are identified and additional costs incurred by collaborative agencies or stakeholders involved with the project are excluded.

\section{FOREST SERVICE NEPA}

NEPA is a far reaching and influential law, pertaining to roughly 50,000 proposed actions per year [9]. A study by the Council on Environmental Quality (CEQ) to gauge NEPA's effectiveness considered some of the structural problems in NEPA's application. The Forest Service's application of the NEPA should be to provide a decision framework that enables society to contribute to the NEPA process. This enables the public to directly provide information about how it would prefer to earn a return on its public assets in the form of benefits, whether these be market or non-market values. These benefits could mean additional jobs for the economy or future benefits of forest health and resilience. However, these 
benefits, and their respective costs of the process are not readily available and can be very complex to decompose. The Government Accountability Office released a report in 2014 stating, "Little information exists on the costs and benefits of completing NEPA analyses. Agencies do not routinely track the cost of completing NEPA analyses, and there is no government-wide mechanism to do so" [10]. This paper hopes to shed some light on what these costs are with respect to timber harvesting on Forest Service land. The archetype of this analysis could be applied more broadly to any acting federal agency.

Each agency of the government has adopted its own procedures for preparing NEPA documents, coordinating with other agencies, and the public comment process [11]. Many times, a follow the leader procedure is enacted where an agency does not have an approved process but follows another agency's process. In addition, project cost accounting is also not uniform across agencies. The resources for each agency's involvement are costly and antiquated. Hard copies or CDs of the entire NEPA document are sent for agency review, and agencies are not able to view other agencies comments in a timely manner [11]. The Department of Energy (DoE) kept generalized cost records for the NEPA process for external contractors to prepare an EIS. For years 2003-2012 the average cost for an EIS was \$1.4 million [10]. Other analyses have focused on the cost of appeals or the cost of litigation [12]. Attempts are made to make a document "litigation proof" often lead to costly documentation along with limited scope of potential alternatives [13]. This difficulty in tracking cost information has also been expressed by the Forest Service. A recent Forest Service report on sourcing for NEPA compliance, said that it is "very difficult to track the actual cost of performing NEPA. Positions that perform NEPA-related activities are currently located within nearly every staff group and are funded by a large number of budget line items. There is no single budget line item or budget object code to follow in attempting to calculate the costs of doing NEPA" [14].

In 2015, the Forest Service published 71 draft and Final EISs in the Federal Register. In comparison to other Federal Agencies, this nearly twice as many as the next two agencies, 40 by both the Bureau of Land Management and U.S. Army Corps of Engineers [15]. EISs take a considerable amount of time and resources to complete. In 2015, the average time from Notice of Intent (NOI) to Draft EIS was 958 days and from Draft EIS to Final EIS an average of 547 days [15]. This makes total days from NOI to Final EIS of 1505 days, or just over 4 years.

In order to try and reduce the amount of excessive paperwork the CEQ has provided guidance and page limits on environmental documents, "the text of final environmental impact statements shall normally be less than 150 pages and for proposals of unusual scope or complexity shall normally be less than 300 pages". 42 EAs were part of the sample consisting of an average page length of 242, while the 18 EISs examined in this analysis have an average page length of 573 pages. This excludes the appendices. Some of the factors identified why agencies fail to meet this limit include: the need to add more detail to avoid litigation, failure to properly scope the document, EAs serving to meet an EIS-level project [11].

\section{THEORETICAL FOUNDATIONS}

Benefit and cost functions have been estimated in a wide array of analyses within the context of forestry and its corresponding environment. An analysis assessing marginal benefits and costs of species preservation estimated a marginal cost curve for spotted owl survival in the Pacific Northwest of the United States [16]. This highly contentious study was estimated to aid in the decision to be made on public policy for maximization of social welfare on the interplay between timber harvest and owl conservation. 
Marcin [17] used a similar approach in estimating a cost function for composite wood products using a translog cost function estimation. He concluded that using this approach is a convenient way to estimate supply and demand equations consistent with primal economic theory. Pizer and Kopp [18] used the following equation:

$$
\text { Costs }=\mathrm{C}_{i}(\mathbf{a}, \mathbf{z}) \text {, }
$$

where $\mathbf{a}$ is a parameter or vector of parameters describing an environmental policy, $\mathbf{z}$ is a vector of parameters summarizing the current economic equilibrium and $C_{i}$ is the cost associated with the $\mathrm{i}$-ith agent. This analysis used a partial equilibrium model considering the relationship between the environment and associated costs when policy effects are transmitted to other markets and the economy equilibrates.

A related analysis by Martin and Voltes-Dorta [19] used the translog cost function for an econometric model to estimate the cost function for airports. Technical and allocative inefficiencies were specified using a Stochastic Frontier method accomplished through Bayesian Inference and Monte Carlo methods. Oliver [20] found that cost elasticities based on a Cobb-Douglas form indicated that proportional increases in capacity and mileage of natural gas pipelines will most likely result in a proportional increase in project cost. This suggests a greater than proportional increase in project cost. In this analysis economies of scale and economies of scope were also estimated and found that economies of scale were exhibited over the capacity margin in natural gas pipelines and economies of scope over the spatial margin of the pipeline network.

The translog production function or cost function occurred in the context of research related to the discovery and definition of new flexible forms of production functions and to the approximation of the constant elasticity of substitution (CES) production function [21]. The translog cost function takes the general form:

$$
\begin{aligned}
\operatorname{Ln} C^{*}= & \alpha_{0}+\alpha_{q} \ln \mathrm{q}+\frac{1}{2} \gamma_{q q}(\ln \mathrm{q})^{2}+\sum_{i} \gamma_{q i} \ln q \ln w_{i}+\sum_{i} \alpha_{i} \ln w_{i} \\
& +\frac{1}{2} \sum i \sum_{j} \gamma_{i j} \ln w_{i} \ln w_{j} .
\end{aligned}
$$

The estimation of a cost function in eqn (2) requires quantity produced $(q)$, observations on costs, outputs (C) and input prices (w) of firms whose behavior is assumed to be costminimizing [19]. Econometric estimation to model cost functions with non-linear characteristics with a non-linear estimator that has properties to make a linear conversion, can be accomplished by using a trans log model estimation. The functional form of the translog cost function allows for a U-shaped average cost curve. This is a reasonable assumption with regards to producing NEPA documents. Quantity for our purposes is project acres. My a priori hypothesis, is that as more project acreage are analyzed the average cost begins to decrease to a certain point. Past this inflection point, as the quantity of project acreage continues to grow, the average cost starts increase as the Forest Service starts experiencing a higher per unit cost. This characteristic illustrates diminishing marginal returns for additional acreage analyzed by the US Forest Service.

Some additional properties of the translog cost function include that input demand is downward sloping, cross price effects are symmetric, a shift in marginal cost with respect to an input price is equal to the shift in the input's demand with respect to output, the sum of own and cross price elasticities are equal to zero, and the proportional increase in all input prices must shift the cost by the same amount holding output constant [22]. 


\subsection{Economies of scale and NEPA}

Both in the private and public sector there has been debates about the efficiency tradeoffs for producing multiple smaller NEPA project documents versus producing one large analysis for an area. For example, consider the Forest Service is planning the NEPA process for multiple areas across a single Forest unit. One strategy is to complete multiple EAs to address impacts for each individual project. If the multiple project areas are in close proximity to one another then one large EIS could be prepared to disclose all of the impacts in one solitary document. A specific example of this logic is a project included in my analysis. The Mass Geis Project EA was originally two adjacent projects that were combined to be analyzed in one document. The result of my analysis will estimate a measure of economy of scale for each of the independent variables, which will answer the question: Is marginal cost decreasing as the volume of acreage increases?

\subsection{Economies of scope and NEPA}

Another unexplored area of NEPA and policy research is the prevalence of cost savings generated by economies of scope. Economies of scope exist in a process when the unit cost of producing two or more products in combination are lower than would occur separate production processes [23]. To illustrate this in the NEPA context consider two areas where multiple EAs will take place, what kind of cost savings does combining the two collaborative efforts to produce multiple documents? For example, when resource specialists are writing the sections for one EA, they could also write analyses concomitantly for an adjacent project area. This would involve coordination between NEPA planners within the Forest Service. This estimation is beyond the scope of this analysis.

\section{EMPIRICAL MODEL}

\subsection{Description of the data}

The data that was gathered for this analysis was obtained through the Forest Service's budgeting departments. The specific database it was obtained from is called the "WorkPlan System (WPS)". WPS is an internal budgeting tool utilized by NEPA planners to estimate costs for Forest Service NEPA projects. The data obtained included all projects that were entered into the WPS and occurred in Region 1 of the Forest Service for fiscal years 20062016. This raw data included all projects that were undertaken on Forest Service land, and not just those that were utilized for timber products.

The original dataset contained 259,220 total observations for Region 1 that were logged in the database during the years 2006-2016 with total planning dollars of \$7.6 billion. Some of the projects within this dataset were undertaken, while some were not. To identify and isolate the different projects that were logged in the database for the use of timber products off of Forest Service land, these observations were queried down by various categorical characteristics.

Project acres (ProjectAcres) represents the amount of acreage that is going to be analyzed for a project that will take place on the land area within a specific National Forest or Forests. For example, a project that was initiated in the Helena National Forest, the NEPA document would define how many acres that the project would encompass. The acreage the Forest Service analyses is generally smaller than the National Forest area. This relates to the total project costs in how efficiently the Forest Units allocates their resources to accomplish an analysis of a project area. 
As discussed previously, whenever NEPA is initiated the projects iteratively fall into three categories depending on the magnitude of the environmental impacts. If it is determined from scoping that the likelihood of impact is small, then a Categorical Exclusion is prepared. If scoping reveals potential significant environmental impacts, then an Environmental Assessment is undertaken. If the EA finds that significant impacts to the quality of the human environment will be affected then the most rigorous of analysis, the Environmental Impact Statement (EIS) is prepared. I created a binary variable to attempt to estimate the rigorousness of analysis and its relationship to the cost of a NEPA project. The Categorical Exclusion (CE) variable is a dummy variable to look at the variation of total costs associated with a project designated as a CE. The variable EA also shares this same meaning, but the project is designated as an Environmental Assessment. The variable EIS is excluded from the regression to eliminate multicollinearity. Within the 77 projects included in the analysis, the distribution of the types of projects are as follows: 17 Categorical Exclusions, 42 Environmental Assessments, and 18 Environmental Impacts Statements. In this regression I look at the cost of all three types of documents, with the CE representing the lower bound and the EIS the respective upper bound. The year variables 2006-2016 represent all years that are analyzed in the dataset.

The variable Idaho site (IDsite) is used as a dummy variable to indicate whether the project lies within the Idaho region of the analysis. This variable is included to look at NEPA cost variation between Idaho and Montana, the two areas where the data was gathered. Summary statistics are provided in Table 1.

\subsubsection{Econometric estimation}

I estimated cost equations using a variety of econometric methods. I ran the first model using a log-log OLS model and the second estimation with a variation of the translog model. The modified translog model for Forest Service cost function takes the form:

$$
\operatorname{Ln} \mathrm{C}^{*}=\alpha_{0}+\alpha_{q} \ln \mathrm{q}+\frac{1}{2} \gamma_{q q}(\ln \mathrm{q})^{2} .
$$

This single cost factor cost function is made with the assumption that labor, capital, and input prices are constant. This assumption can be made for multiple reasons. There are various agents that work on the NEPA documents that are prepared for the public. This includes various biologists (wildlife, fisheries, etc.), hydrologists, botanists, silvaculturists, and a NEPA lead to manage the project. This is not a complete list but illustrates the type of personnel that completes these analyses. The NEPA lead estimates the number of days this team of resource specialists will need to complete the NEPA process. This is how budgets are established to estimate project completion costs. In my analysis resource specialists and NEPA planners work in close proximity to one another (from forest to forest). For example, those working in the Helena National Forest and those working in the adjacent Flathead National Forest should have very similar labor costs. This allows me to assume that labor

Table 1: Summary statistics.

\begin{tabular}{|l|c|c|c|c|}
\hline \multirow{2}{*}{ Summary statistics } & \multicolumn{4}{|c|}{ Variables } \\
\cline { 2 - 5 } & Mean & Maximum & Minimum & Median \\
\hline $\begin{array}{l}\text { Total cost } \\
\text { (77 observations) }\end{array}$ & $\$ 301,397$ & $\$ 1,376,206$ & $\$ 2,000$ & $\$ 219,452$ \\
\hline $\begin{array}{l}\text { Project acreage } \\
\text { (77 observations) }\end{array}$ & 23,257 & 135,000 & 30 & 16,468 \\
\hline
\end{tabular}


prices are constant for the econometric model. Given the close proximity of the forests, they are likely to face the same input prices and capital costs. This is further exhibited through public information regarding wages of Federal employees. In Region 1 resource specialist salaries in all counties in the Nez Perce Clearwater and the Helmville/Garnet Range have a $14.35 \%$ pay adjustment (www.federalpay.org/gs/2016).

One of the concerns with OLS estimation is the assumption that the error term has constant variance, or that the error terms are homoscedastic. When this assumption is violated then heteroscedasticity is present and OLS remains unbiased, but the standard errors are biased. When running an OLS model heteroscedasticity is a major concern as it can invalidate statistical tests of significance because the modelling errors are uncorrelated and uniform [24], [25]. I conducted multiple tests to detect for the presence of heteroscedasticity. The translog model estimations are the subject of these tests, given their more robust results.

As a starting point, I performed a visual test for the presence of heteroskedasticity by examining the relationship between the fitted values in the estimation and the residuals of the observations. When heteroscedasticity is present the error-terms may increase as the values of the IVs increase (non-constant variance). With a small sample the residuals will be somewhat larger near the mean of the distribution than at the extremes, as opposed to a large sample when you would ideally see an envelope of even width of the residuals. A visual test in this case, does not provide us with enough information to dismiss concerns about heteroscedasticity. There are a variety of statistical tools in our toolbox to further address this issue.

A Breusch-Pagan-Godfrey (BPG) tested in a null hypothesis (Ho) that the model has constant variance, or that the error terms are homoscedastic. If the $\mathrm{p}$ value of the BPG test is less than 0.05 then we reject the null hypothesis. For the resulted p value of 0.3415 in my test, we fail to reject the null hypothesis. A White Test was also performed and resulted in a p-value of .44, and we also fail to reject the null hypothesis of homoskedasticity.

\subsubsection{Left and right-hand side variables}

The left-hand side (LHS) of the equation (in logarithmic form) is composed of total costs of individual projects. The average total costs for each type of project (CE, EA, and EIS) are summarized in Table 2.

The right-hand side (RHS) variables also in logarithmic form are project acres (lnProjectAcres), project acres squared (InProjectAcresSq), CE, EA, ESA, 2006, 2007, 2008, 2009, 2010, 2011, 2012, 2013, 2014, 2015, and Idaho sites (IDsite). The interaction effects for project acres and project years is also estimated.

The results for both regressions, log-log and translog, are shown in Table 3. Comparing these results, the r-squared increases from the log-log model to the translog model from $66 \%$ to $78 \%$. The independent variable CE is statistically significant at the $95 \%$ confidence level and has a negative coefficient in the log-log regression but is not significant in the translog model. The variable CE is significant in both estimations. This variable represents a project that occurs and that is the least intensive of analysis, a Categorical Exclusion. The results of the model estimate that the cost of a CE on average are 100\% less than an EIS. The ESA variable is also significant and positive, but the magnitude of impact on total cost dropped

Table 2: Average project cost by type of analysis.

\begin{tabular}{|c|c|c|}
\hline CE & EA & EIS \\
\hline$\$ 113,683$ & $\$ 256,247$ & $\$ 582,84$ \\
\hline
\end{tabular}


Table 3: Regression estimates (standard errors in parenthesis); *90\% confidence **95\% confidence.

\begin{tabular}{|c|c|c|}
\hline \multirow{2}{*}{ Variable } & \multicolumn{2}{|c|}{ Dependent variable: $\ln$ Project Cost } \\
\hline & Log-Log & Translog \\
\hline $\ln$ ProjectAcres & $\begin{array}{c}0.383 \\
(0.921)\end{array}$ & $\begin{array}{l}0.052 \\
(1.13)\end{array}$ \\
\hline $\operatorname{lnProjectAcresSq}$ & $\begin{array}{c}-0.004 \\
(0.049) \\
\end{array}$ & $\begin{array}{c}0.018 \\
(0.111) \\
\end{array}$ \\
\hline $\mathrm{CE}$ & $\begin{array}{c}-1.01^{* *} \\
(0.46)\end{array}$ & $\begin{array}{c}-1.74 * * \\
(0.461) \\
\end{array}$ \\
\hline EA & $\begin{array}{c}-0.432 * * \\
(0.208) \\
\end{array}$ & $\begin{array}{c}-0.322 \\
(0.198) \\
\end{array}$ \\
\hline ESA & $\begin{array}{c}0.587 * * \\
(0.208)\end{array}$ & $\begin{array}{c}0.509 * * \\
(0.200)\end{array}$ \\
\hline Y2007 & $\begin{array}{c}-0.795 \\
(0.491) \\
\end{array}$ & $\begin{array}{c}28.7 \\
(33.49) \\
\end{array}$ \\
\hline Y2008 & $\begin{array}{c}0.283 \\
(0.391) \\
\end{array}$ & $\begin{array}{c}-1.87 \\
(.3 .80) \\
\end{array}$ \\
\hline Y2009 & $\begin{array}{c}0.129 \\
(0.441)\end{array}$ & $\begin{array}{l}-4.25 \\
(3.59)\end{array}$ \\
\hline Y2010 & $\begin{array}{c}-0.395 \\
(0.447) \\
\end{array}$ & $\begin{array}{c}6.91 \\
(9.57) \\
\end{array}$ \\
\hline Y2011 & $\begin{array}{c}0.212 \\
(0.334) \\
\end{array}$ & $\begin{array}{l}-0.86 \\
(3.20) \\
\end{array}$ \\
\hline Y2012 & $\begin{array}{l}0.0163 \\
(0.317) \\
\end{array}$ & $\begin{array}{l}-3.16 \\
(3.16) \\
\end{array}$ \\
\hline Y2013 & $\begin{array}{c}0.132 \\
(0.350)\end{array}$ & $\begin{array}{l}-2.55 \\
(3.67)\end{array}$ \\
\hline Y2014 & $\begin{array}{l}-0.278 \\
(0.63)\end{array}$ & $\begin{array}{c}3.51 \\
(3.24)\end{array}$ \\
\hline Y2015 & $\begin{array}{l}0.626^{*} \\
(0.343)\end{array}$ & $\begin{array}{c}3.07 \\
(3.48)\end{array}$ \\
\hline IDsite & $\begin{array}{c}0.353 \\
(0.213) \\
\end{array}$ & $\begin{array}{c}0.300 \\
(0.220) \\
\end{array}$ \\
\hline $\ln$ ProjAcres 2007 & & $\begin{array}{c}-2.88 \\
(3.25) \\
\end{array}$ \\
\hline $\ln$ ProjAcres2008 & & $\begin{array}{c}0.201 \\
(0.372) \\
\end{array}$ \\
\hline $\ln$ ProjAcres2009 & & $\begin{array}{c}0.471 \\
(0.365) \\
\end{array}$ \\
\hline $\ln$ ProjAcres 2010 & & $\begin{array}{c}-0.776 \\
(0.980)\end{array}$ \\
\hline $\ln$ ProjAcres2011 & & $\begin{array}{c}0.09 \\
(0.314)\end{array}$ \\
\hline
\end{tabular}


Table 3: Continued.

\begin{tabular}{|l|c|c|}
\hline \multirow{2}{*}{ Variable } & \multicolumn{2}{|c|}{ Dependent variable: $\ln$ Project Cost } \\
\cline { 2 - 3 } & Log-Log & Translog \\
\hline \multirow{2}{*}{$\ln$ ProjAcres2012 } & & $\begin{array}{c}0.3 \\
(0.301)\end{array}$ \\
\hline \multirow{2}{*}{$\ln$ ProjAcres2013 } & & $\begin{array}{c}0.258 \\
(0.363)\end{array}$ \\
\hline \multirow{2}{*}{$\ln$ ProjAcres2014 } & & -0.407 \\
& & $(0.314)$ \\
\hline \multirow{2}{*}{$\ln$ ProjAcres2015 } & & -0.251 \\
& & $(0.46)$ \\
\hline \multirow{2}{*}{$\mathrm{B}_{0}$} & $8.77^{* *}$ & $10.97 *$ \\
& $(4.18)$ & 0.7838 \\
\hline $\mathrm{R}^{2}$ & 0.6587 & $0.06)$ \\
\hline
\end{tabular}

from $59 \%$ to $51 \%$. The interpretation of these results is that if an endangered species is present in the project area, the project experiences $51 \%-59 \%$ higher costs, ceteris paribus.

\subsubsection{Economies of scale estimation}

The translog function allows for both positive and negative scale effects, average cost can both decrease and increase across the range of the cost function.

A standard expression to estimate scale effects is:

$$
\varepsilon_{\mathrm{q}}=\left[\frac{\partial \ln C^{*}}{\partial \ln q}\right]
$$

This estimation from eqn (4) provides a value that explains the percentage change in cost, given a percentage change in quantity, or an elasticity. For my model $\varepsilon_{\mathrm{q}}=0.05+0.018$ (lnprojectacres). If we use these results to estimate a 5,000 acre increase in project size, then there would be $57.9 \%$ increase in the cost of the project, all else equal.

\section{DISCUSSIONS}

In this article, I examined the NEPA costs associated with timber projects occurring on Forest Service land. This was developed within the framework of an econometric model from a database used to log budgeting plans for NEPA projects. A variation of a translog cost function and a log-log regression were run to select an appropriate means to approximate the cost function of the Forest Service's NEPA analyses. The translog cost function provided more favorable results. The implications of these results provide information for cost-benefit analyses that are undertaken to look at the economic viability of timber projects on Forest Service land. It is my hope that my research furthers the academic and public scrutiny of a process that lacks central fiscal accountability.

The calculation and estimation of NEPA costs remains a contentious issue for the government agency leading the analysis, the stakeholders, and private interests. It is worth positing that public agencies are potentially not concerned with the cost of NEPA because they are incurring a cost of providing information about a public good; that it's value is immeasurable. Another potential means of curtailing the costs of NEPA is the integration of private partners into the NEPA process. This could be in the form of outsourcing the process to an external consulting firm or enable a private partner to become part of the process. 
Private companies would have incentive to help make NEPA more efficient and could be reviewed by the Forest Service personnel for thoroughness.

Another way to increase the efficiency of NEPA is to use an integrated interagency collaboration network. This could link projects with similarities and possible overlap amongst tasks. One under-researched stage of the environmental impact statement is the scoping practice [26]. If the scoping process was improved, a more efficient trajectory for the project could be created, which would make the NEPA documents less costly. It is my hope that this paper serves as a foundation to further the literature on estimating and understanding NEPA costs. Other areas of research include economies of scope estimates for NEPA projects and expanding the analysis area to contrast with other regions of the US Forest Service.

\section{REFERENCES}

[1] Dietz, T., Ostrom, E. \& Stern, P.C., The struggle to govern the commons. Science, 302(5652), pp. 1907-1912, 2003.

[2] Gregory, R., Failing, L., Harstone, M., Long, G., McDaniels, T. \& Ohlson, D., Structured Decision Making: A Practical Guide to Environmental Management Choices, John Wiley \& Sons, 2012.

[3] Karjalainen, T.P., Marttunen, M., Sarkki, S. \& Rytkönen, A.M., Integrating ecosystem services into environmental impact assessment: An analytic-deliberative approach. Environmental Impact Assessment Review, 40, pp. 54-64, 2013.

[4] Renn, O., The challenge of integrating deliberation and expertise. Risk Analysis and Society: An Interdisciplinary Characterization of the Field, ed. T. McDaniels, Cambridge University Press: Cambridge, pp. 289-366, 2004.

[5] Broussard, S.R. \& Whitaker, B.D., The Magna Carta of environmental legislation: A historical look at 30 years of NEPA-Forest Service litigation. Forest Policy and Economics, 11(2), pp. 134-140, 2009.

[6] USDA Forest Service, The Process Predicament: How Statutory, Regulatory, and Administrative Factors Affect National Forest Management, USDA Forest Service: Washington, DC, 2002.

[7] Management Analysis, Inc., Feasibility Study of Activities Related to National Environmental Policy Act (NEPA) Compliance in the US Forest Service, Management Analysis, Incorporated: Vienna, VA, 2007.

[8] Triebs, T.P., Saal, D.S., Arocena, P. \& Kumbhakar, S.C., Estimating economies of scale and scope with flexible technology. Journal of Productivity Analysis, 45(2), pp. 173-186, 2016.

[9] Karkkainen, B.C., Toward a smarter NEPA: Monitoring and managing government's environmental performance. Colum. L. Rev., 102, p. 903, 2002.

[10] Government Accountability Office (GAO), National Environmental Policy Act: Little Information Exists on NEPA Analyses, GAO-14-370, 2014.

[11] Lyles, K.C., Expediting the NEPA process via a Document Management System and Virtual GIS-Based NEPA platform. Environmental Practice, 19(3), pp. 139-147, 2017.

[12] Kaiser, B.A., The national environmental policy act's influence on USDA forest service decision-making, 1974-1996. Journal of Forest Economics, 12(2), pp. 109130, 2006.

[13] Council on Environmental Quality (US), The National Environmental Policy Act: A Study of its Effectiveness after Twenty-Five Years, Council on Environmental Quality, Executive Office of the President, 1997. 
[14] USDA Forest Service, Competitive Sourcing Program Office, Feasibility Study of Activities Related to National Environmental Policy Act (NEPA) Compliance, Washington, DC, 2007.

[15] National Association of Environmental Professionals (NAEP), Annual NEPA Report 2015, 2016.

[16] Montgomery, C.A. \& Adams, D.M., The marginal cost of species preservation: The northern spotted owl. Journal of Environmental Economics and Management, 26(2), pp. 111-128, 1994.

[17] Marcin, T.C., Cost function approach for estimating derived demand for composite wood products. InSymposium on Systems Analysis in Forest Resources, Charleston, SC, 1991.

[18] Pizer, W.A. \& Kopp, R., Calculating the costs of environmental regulation. Handbook of Environmental Economics, 3, pp. 1307-1351, 2005.

[19] Martín, J.C. \& Voltes-Dorta, A., The econometric estimation of airports' cost function. Transportation Research Part B: Methodological, 45(1), pp. 112-127, 2011.

[20] Oliver, M.E., Economies of scale and scope in expansion of the US natural gas pipeline network. Energy Economics, 52, pp. 265-276, 2015.

[21] Pavelescu, F.M., Methodological considerations regarding the estimated returns to scale in case of Cobb-Douglas production function. Procedia Economics and Finance, 8, pp. 535-542, 2014.

[22] Christensen, L.R. \& Greene, W.H., Economies of scale in US electric power generation. Journal of Political Economy, 84(4, Part 1), pp. 655-676, 1976.

[23] Baumol, W.J., Contestable markets: an uprising in the theory of industry structure. Microtheory: Applications and Origins, ed. W.J. Baumol, pp. 40-54, 1986.

[24] Goldberger, A.S., Econometric Theory, John Wiley, 1964.

[25] Johnston, J. \& DiNardo, J., Econometric Methods, New York, 1972.

[26] Snell, T. \& Cowell, R., Scoping in environmental impact assessment: balancing precaution and efficiency? Environmental Impact Assessment Review, 26(4), pp. 359376, 2006. 